\title{
A new record of Siler collingwoodi (Araneae: Salticidae) from Japan
}

\author{
Yuki G. Baba \\ National Institute for Agro-Environmental Sciences, 3-1-3 Kannondai, Tsukuba-shi, Ibaraki, 305-8604 Japan \\ E-mail: ybaba@affrc.go.jp
}

\begin{abstract}
Siler collingwoodi (O. Pickard-Cambridge, 1871) (Salticidae) was newly recorded from Japan based on specimens collected from Iriomotejima Island at Okinawa Prefecture. This species is easily distinguishable from the other Japanese jumping spiders by its appearance and genital morphology.
\end{abstract}

Key words - taxonomy, new record, Ryukyu Islands

\section{Introduction}

The salticid spider genus Siler Simon, 1889 (Araneae: Salticidae) currently contains 11 species in the world (Prószyński 2007), some of which are known as ant-eating spider (Jackson et al. 1998; Touyama et al. 2008). In Japan, one species, Siler vittatus (Karsch, 1879), is known from the main islands (Honshu, Shikoku and Kyushu) (Ono 2009). Recently, I recognized the occurrence of $S$. collingwoodi (O. Pickard-Cambridge, 1871), that has been recorded only from China (Prószyński 1985, 2007), in the South-West Islands of Japan after examining the materials obtained from Iriomotejima Island. Here, I present the morphological characteristics of this species based on the Japanese specimens. The specimens used in this paper are deposited in the collection of the National Museum of Nature and Science, Tokyo (NSMT). I wish to express thanks to Dr. Akio Tanikawa, The University of Tokyo for offering specimens used in this study, and Mr. Hiroyoshi Ikeda, Kanagawa and Mr. Kazuki Yamamuro, Kagoshima for providing valuable information about this species.

\section{Siler collingwoodi (O. Pickard-Cambridge, 1871)} [Japanese name: Karaobi-haetori]

(Figs. 1-6)

Salticius collingwoodi O. Pickard-Cambridge 1871, pp. 617, 621 [male holotype from Hong Kong preserved in Oxford].

Maevia collingwoodi: Thorell 1892, p. 474.

Cosmophasis collingwoodi: Simon 1901, p. 549.

Siler collingwoodi: Prószyński 1985, pp. 75-77. figs. 24-29; Song \& Chai 1991, p. 14, figs. 3A-D; Song, Zhu, \& Chen 1999, p. 558, figs. 315J, 316A.

Specimens examined. All the specimens were collected by A. Tanikawa in Iriomotejima Is., Okinawa Pref., Japan. 1우, 24-VIII-1987 (NSMT-Ar 8558), Funaura; 1우, 11-VIII1985 (NSMT-Ar 8559), 10, 16-VIII-1988 (NSMT-Ar
8560), Sonai; 13, 3-V-1984 (NSMT-Ar 8561), 1우, 1-IV1985 (NSMT-Ar 8562), 10, 16-VIII-1985 (NSMT-Ar 8563), Komi; 1우, 30-XII-1986 (NSMT-Ar 8564), 1우, 19VIII-1988 (NSMT-Ar 8565), Otomi; 1 10, 27-III-1985 (NSMT-Ar 8566), 10 ${ }^{\curvearrowright}, 15-\mathrm{VIII}-1987$ (NSMT-Ar 8567), Ohara.

Description. Based on the Japanese specimens $10^{7}$ (NSMT-Ar 8560), 1우 (NSMT-Ar 8565), measurements in parentheses indicate the range among specimens used in this paper. Body length: 33.65 (3.06-4.47), 우4.59 (4.59-4.94). Carapace length: o1 1.88 (1.69-2.31), 우2.25 (2.19-2.25). Carapace width: ð1.31 (1.19-1.63), 우1.56 (1.56-1.69).

Eye fields (The following abbreviations are used: ALE, anterior lateral eye; AME, anterior median eye; PLE, posterior lateral eye; PME, posterior median eye. The distances between eyes are expressed as following. e.g. ALE-AME.) Eye fields. ALE-ALE: ${ }^{\top 1} 111(0.94-1.29)$, ㅇ⒈26 (1.261.29). PLE-PLE: $\overbrace{}^{\top} 1.20 \quad\left(1.06^{-1.40)}\right.$, ㅇ⒈40 (1.40-149). ALE-PLE: ${ }^{\top} 0.83$ (0.74-1.00), 우 0.91 (0.91-1.00). ALEPME: Љ 0.43 (0.34-0.49), 우.49 (0.49-0.54). ALE-PLE/ carapace length: o $0.44(0.43-0.46)$, $+0.41 \quad(0.41-0.46)$. ALE-ALE/PLE-PLE: ${ }^{\top} 0.93$ (0.88-0.93), $+0.90(0.87-0.90)$. AME diameter: ${ }^{\top} 0.34(0.29-0.40)$, 우 $0.37(0.37-0.40)$. ALE/ AME: $\delta^{\top} 0.63(0.54-0.63)$, 우0.62 (0.57-0.64). ALE/PLE: $\sigma^{\top}$ $1.00\left(0.86^{-1.00)}\right.$, 우1.00 (0.94-1.00). PME/PLE: ${ }^{\top} 0.29$ $(0.19-0.29)$, 우 $0.25(0.22-0.25)$.

Length of legs as shown in Table 1.

Male palp. Embolus long, bent sidewards and then bending again and running anteriorwards, slightly undulating (Figs. 1-2). Bulbus almost square with round angles, with angular posterior extension and small ventral protuberance in its anterior half. Tibial apophysis slightly bending.

Female genitalia. Epigynum and internal genitalia of female as shown in Figs. 3-4.

Coloration and markings. Male. Carapace basically red, covered with bluish metallic hairs; marginated with white hairs. Areas surrounded by eyes dark. Leg I: tibia, patella and femur dark brown; and tarsus light brown. Leg II-IV 
Table 1. Measurements of leg segments of Siler collingwoodi ( $\lesssim / P$; in mm)

\begin{tabular}{ccccccc}
\hline Leg & Femur & Patella & Tibia & Metatarsus & Tarsus & Total \\
\hline I & $1.11 / 1.17$ & $0.54 / 0.54$ & $0.77 / 0.77$ & $0.60 / 0.60$ & $0.51 / 0.51$ & $3.53 / 3.59$ \\
II & $0.86 / 0.86$ & $0.40 / 0.49$ & $0.60 / 0.63$ & $0.54 / 0.54$ & $0.37 / 0.43$ & $2.77 / 2.95$ \\
III & $0.86 / 0.94$ & $0.43 / 0.49$ & $0.60 / 0.63$ & $0.71 / 0.71$ & $0.43 / 0.46$ & $3.03 / 3.23$ \\
IV & $1.20 / 1.29$ & $0.49 / 0.54$ & $0.91 / 1.00$ & $0.97 / 1.14$ & $0.57 / 0.57$ & $4.14 / 4.54$ \\
\hline
\end{tabular}
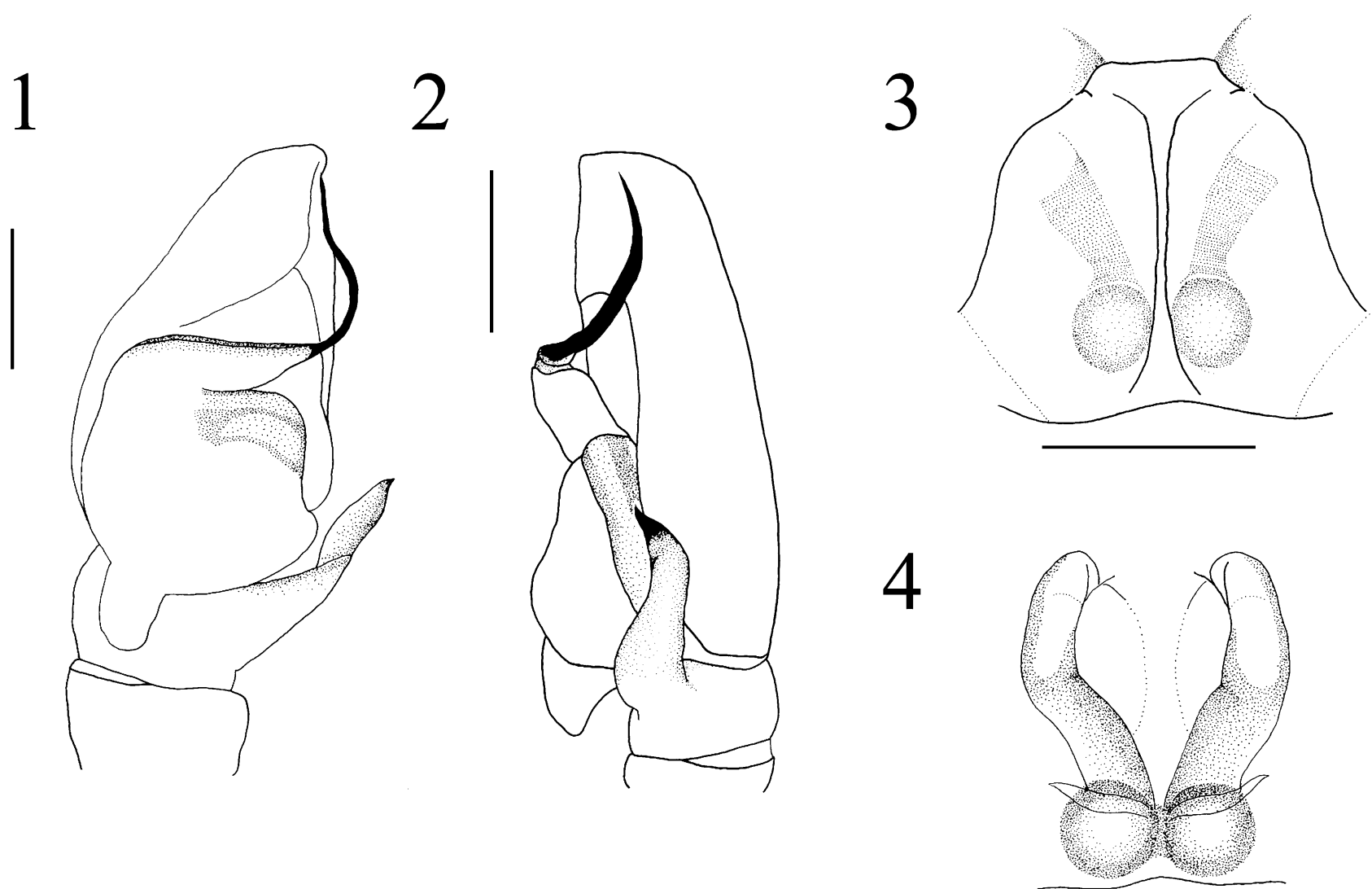

Fig. 1-4. Siler collingwoodi (O. Pickard-Cambridge, 1871), Јै (NSMT-Ar 8560) and ㅇ (NSMT-Ar 8565). 1, Male left palp, ventral view; 2, same, retrolateral view; 3, epigynum, ventral view; 4, female internal genitalia, dorsal view. (Scales: $0.1 \mathrm{~mm}$ ).
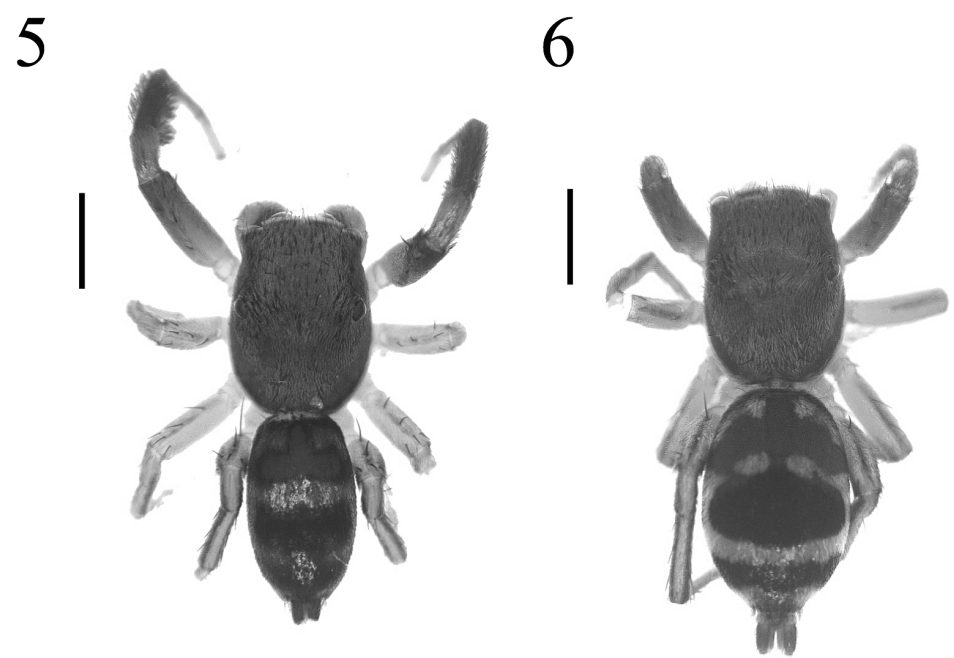

Fig. 5-6. Siler collingwoodi (O. Pickard-Cambridge, 1871). 5, Male, dorsal view (NSMT-Ar 8566); 6, female, dorsal view (NSMT-Ar 8558). (Scales: $1 \mathrm{~mm}$ ). 
light brown. Dorsum of abdomen covered with silver hairs, except for characteristic red marking and black bands (Fig. 5).

Female. Coloration and markings similar to those of male (Fig. 6).

Variation. Coloration and markings are highly variable with the degree of hair loss.

Distribution. Japan (Iriomotejima Is.) and China (Hong Kong, Hainan).

Remarks. Siler collingwoodi can be easily distinguished from the other Japanese jumping spiders by the general appearance and genital morphology.

\section{References}

Jackson, R. R., Li, D., Barrion, A. T. \& Edwards, G. B. 1998. Prey- capture techniques and prey preferences of nine species of anteating jumping spiders (Araneae: Salticidae) from the Philippines. New Zeal. J. Zool., 25: 249-272.

Ono, H. (ed.) 2009. The Spiders of Japan: with keys to the families and genera and illustrations of the species. Tokai University Press, Kanagawa, 738pp.

Prószyński, J. 1985. On Siler, Silerella, Cyllobelus and Natta (Araneae, Salticidae). Ann. Zool., 39: 69-85.

Prószyński, J. 2007. Monograph of the Salticidae (Araneae) of the world. http://salticidae.org/salticid/main.htm

Touyama, Y., Ihara, Y. \& Ito, F. 2008. Argentine ant infestation affects the abundance of the native myrmecophagic jumping spider Siler cupreus Simon in Japan. Insect. Soc., 55: 144-146.

Received November 26, 2009 / Accepted March 16, 2010 